\title{
Screening of Different Artemisia spp. from Western Ghats of Maharashtra for an Anti-Malarial Compound-Artemisinin
}

\author{
Vishnu Shukla1 ${ }^{1}$, Zarna Pala ${ }^{2}$, Anshu Alok ${ }^{1}$, Neetin Desai ${ }^{3 *}$ \\ ${ }^{1}$ Department of Biotechnology, National Agri-Food Biotechnology Institute, Mohali, India \\ ${ }^{2}$ Department of Biological Sciences, Birla Institute of Technology and Science (BITS), VidyaVihar Campus, Pilani, \\ India \\ ${ }^{3}$ Department of Biotechnology and Bioinformatics, Dr. D. Y. Patil University, Mumbai, India \\ Email: shuklavrk@gmail.com, anshualok2@gmail.com, zarnapala@gmail.com, ${ }^{*}$ neetindesai@gmail.com
}

Received 8 April 2015; accepted 27 June 2015; published 30 June 2015

Copyright (C) 2015 by authors and Scientific Research Publishing Inc.

This work is licensed under the Creative Commons Attribution International License (CC BY).

http://creativecommons.org/licenses/by/4.0/

(c) (1) 0pen Access

\begin{abstract}
Artemisinin, an endoperoxide sesquiterpene lactone has proven effective in treating drug resistant cases of malaria and cancer. Artemisia annua [sweet wormwood] is the sole source for artemisinin production in many countries. To counter the low content in leaves and costly chemical synthesis process in India, alternative ways to produce artemisinin have been sought. In current study, we collected $A$. pallens, $A$. japonica and $A$. nilagirica from Western Ghats of Maharashtra, India and analyzed artemisinin content. Samples were extracted from leaves and florets in various extraction conditions and analyzed using different chromatographic techniques. Thin layer chromatography (TLC) and high performance thin layer chromatography (HPTLC) analysis showed the presence of compound with endoperoxide linkage in $A$. nilagirica. High performance liquid chromatography (HPLC) analysis showed the detection of artemisinin in methylene dichloride florets extract of $A$. japonica, but the concentration was too low $[1.3 \mathrm{mg} / \mathrm{g}$ dry wt.] for further analyses. Gas chromatography/mass spectrometry (GC/MS) analysis identified structurally important components in the $A$. nilagirica ethyl acetate extract which explores the biosynthetic pathway of artemisinin from its most important precursor amorpha-4,11-diene. This is the first report of chromatographic screening of these Indian varieties of Artemisia spp. for artemisinin content.
\end{abstract}

\section{Keywords}

Artemisia pallens, Artemisia nilagirica, Artemisia japonica, Endoperoxide, Amorpha-4,11-diene

\footnotetext{
${ }^{*}$ Corresponding author.
}

How to cite this paper: Shukla, V., Pala, Z., Alok, A. and Desai, N. (2015) Screening of Different Artemisia spp. from Western Ghats of Maharashtra for an Anti-Malarial Compound-Artemisinin. American Journal of Plant Sciences, 6, 1619-1632. 


\section{Introduction}

Artemisia annua (family Asteraceae) commonly called Quinghao, sweet wormwood, is an annual herb native to China [1]. The plant has been introduced in India for experimental cultivation [2]. Diethyl ether extract of $A$. annua has excellent effect against malaria and artemisinin is identified as a main active ingredient [3]. Artemisinin is an endoperoxide sesquiterpene lactone effective against several strains of Plasmodium, malarial parasite. Accumulation of artemisinin is mainly reported in leaves, green stems (trace amounts), florets and seeds [4]-[7].

Several studies in tissue culture have shown potential and convenience of using roots transformed by Agrobacterium rhizogenes for the biosynthesis of secondary metabolites in numerous species [8]. Genetically transformed roots of $A$. annua showed potentially higher production rates of artemisinin products in just a few days, providing at the same time cleaner extraction sources for these biochemical compounds [9]-[11].

A. annua plant still remains sole source for artemisinin and relatively low yield in available germplasms became serious limitation in large-scale production of artemisinin [12] [13]. Several countries reported variation in artemisinin content in strains of A. annua, 0.03\% - 0.22\% in European origin [14], 0.05\% - 0.21\% in USA [15]. Since its chemical synthesis is difficult and economically unviable [16], plant source has been considered an attractive alternative for the production of this metabolite. Considering the current scenario of artemisinin production from A. annua in India, the need to screen different Indian Artemisia species has gained importance. In present study, an attempt has been made for the "Screening of Artemisia species from Western Ghats of Maharashtra for anti-malarial compound-Artemisinin”.

\section{Result \& Discussion}

\subsection{TLC Analysis}

Two different extract were prepared to assess the artemisinin detection. In the Hexane extract of plants, no spots were found to be related to standard spot $\left(\mathrm{R}_{\mathrm{f}} 0.63\right)$ of artemisinin. However, TLC analysis of dichloromethane leaves extract of $A$. pallens and $A$. japonica showed $R_{\mathrm{f}}$ of 0.80 and 0.78 respectively with a very faint pink spot and leaves extract of $A$. nilagirica showed intense pink spot with $\mathrm{R}_{\mathrm{f}}$ value of 0.38 (Table 1 and Figure 1 ). Since, pink colour denotes the presence of peroxide linkage in the structure, a compound related to artemisinin was present in the samples (higher in A. nilagirica).

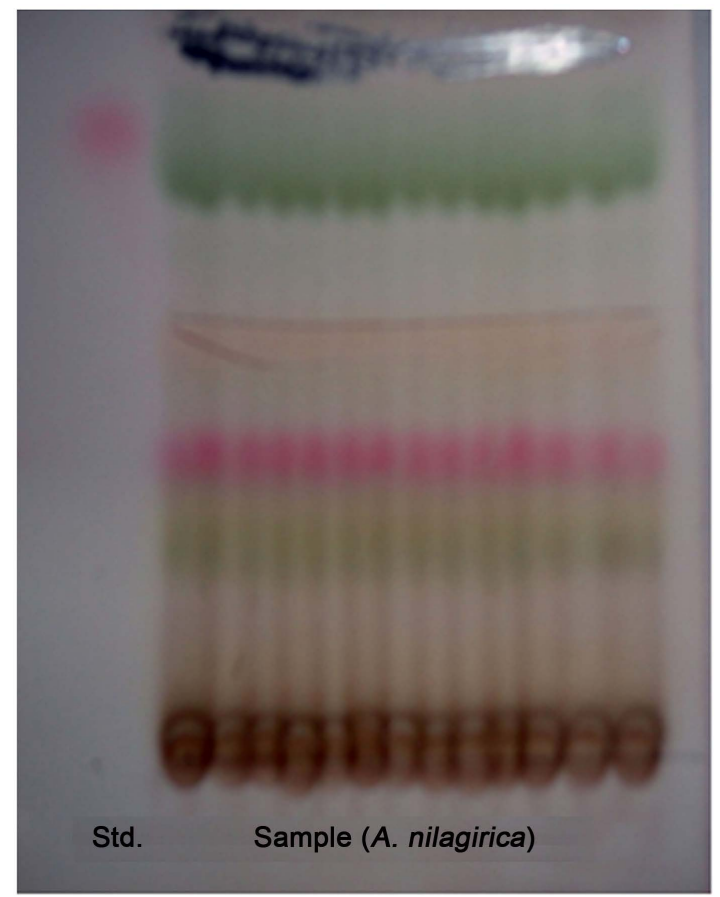

Figure 1. Pink band showing the presence of compound with peroxide linkage in A. nilagirica. 
Table 1. TLC analysis. The $\mathrm{R}_{\mathrm{f}}$ value of leaves and florets of A. pallens, A. nilagirica and A. japonica $\left(\mathrm{R}_{\mathrm{f}}\right.$ for standard is 0.63$)$.

\begin{tabular}{cccccc}
\hline \multirow{2}{*}{ Sample } & \multicolumn{2}{c}{ Kolhapur } & \multicolumn{2}{c}{ Panchgani } & Lonavala \\
\cline { 2 - 5 } & A. pallens & A. nilagirica & A. japonica & A. nilagirica & A. nilagirica \\
\hline \multirow{2}{*}{ Leaves } & 0.80 & 0.41 & 0.78 & 0.38 & 0.39 \\
Florets & 0.78 & 0.53 & 0.80 & 0.47 & 0.50 \\
\hline
\end{tabular}

\subsection{HPTLC Analysis}

For HPTLC analysis, Toluene extract was prepared for the solvent extraction. The $\mathrm{R}_{\mathrm{f}}$ value of standard obtained was 0.60 units. The intensity of fluorescent pink band in spiked samples was found to be more intense in comparison to normal plant extracts (Figure 2). The spiked samples of A. pallens, A. nilagirica showed same $\mathrm{R}_{\mathrm{f}}$ value (Figure 3 and Figure 4 ) whereas leaves extract of $A$. pallens and A. nilagirica showed difference in $R_{f}$ values in the range of \pm 2 with that of standard. Hence, amount of artemisinin in the samples was very low to be detected and further more sensitive technique has to be applied.

\subsection{Determination of Artemisinin by HPLC}

Artemisinin detection in collected Artemisia species was found to be difficult and results are shown in Table 2. The leaves and florets extract of A. japonica (Panchagani) showed same elution time (18.3) with that of standard (Table 2 and Table 3) and content of artemisinin was found to be 0.4 and $1.3 \mathrm{mg} / \mathrm{g}$ dry wt. respectively (Table 3). Since artemisinin and dihydroartemisinin are thermally labile and lack UV or fluorescent chromophores [17] [18], as well as functional groups for derivatization, development of sensitive and specific analytical methods for determination of these compounds is a challenging problem. Hence, presence of artemisinin cannot be confirmed for all samples except A. japonica. Therefore, further standardization and optimization of protocol for the detection of artemisinin using HPLC in these species is required. Analysis of underivatized Artemisinin at RT of 5.05 by HPLC-UV in A. annua was reported by Ferreira J and Gonzalez JM in 2009 [19].

\subsection{Finger Printing by GC-MS Analysis}

GC-MS analysis of methanol extract and ethyl acetate extract revealed the presence of structures mainly components of essential oil in Artemisia species. Table 4 and Table 5 postulate the found structures in standard artemisinin sample and ethyl extract of $A$. nilagirica respectively, after comparing the library of known structures. Figure 5 represents the structures including cis-lanceol, eudesmol, $\gamma$-muurolene, Germacrene D identified in ethyl acetate of $A$. nilagirica with retention time 12.6, 13.15, 11.42 and 11.42 respectively. More interestingly, these structures were found to be closely related to the structure of amorpha-4,11-diene (Figure 6). Amorpha-4,11-diene with a amorphane skeleton is a direct precursor of Artemisinin formed from Farnesyl diphosphate (FPP) by amorpha-4,11-diene synthase (ADS) [20]. Amorpha-4,11-diene is a major product formed by the action of ADS, but other minor products such as, sesquiterpene alcohol, sesquiphellandrene, $\gamma$-muurolene are formed probably due to quenching of carbon in amorphanecation by water or elimination of hydrogen from bisabolylcation [21]. These minor products were present in leaves of A. nilagirica (Table 4). As an sesquiterpene synthase, ADS shares a metal ion ( $\mathrm{Mn+}$ or $\mathrm{Mg}^{+}$) to stabilize the negatively charged pyrophosphate group of Farnesyl diphosphate [22] and highly conserved sequence [I, L, V] DDxxD [E] serves to bind metal ions in all terpene synthases [23]-[26]. $\gamma$-muurolene has an muurolan skeleton with cis-fused decalin ring and differ in its relative stereochemistry at C7-position as compared to amorphane skeleton of amorpha-4,11-diene [21]. On the basis of GC-MS data we tried to establish possible metabolic pathways for $\gamma$-muurolene in A. nilagirica instead of amorpha-4,11-diene.

\subsubsection{Formation of $\gamma$-Muurolene from FPP by ADS}

The pathway reported for amorpha-4,11-diene by Geoffery (2010) and Edward et al. (2000) was reinvestigated [20] [21]. Mechanistic formation of $\gamma$-muurolene from Farnesyl diphosphate (FPP) catalyzed by ADS is postulated (Figure 7). The first step is ionization of FPP where paired diphosphate anion is transferred to C3 giving nerolidyldiphosphate, this intermediate generates a cisoid form by rotation around C2-C3 bond. The cisoid form allows bond formation between C1 and C6 which results in the first ring closure and a bisabolylcation. The 


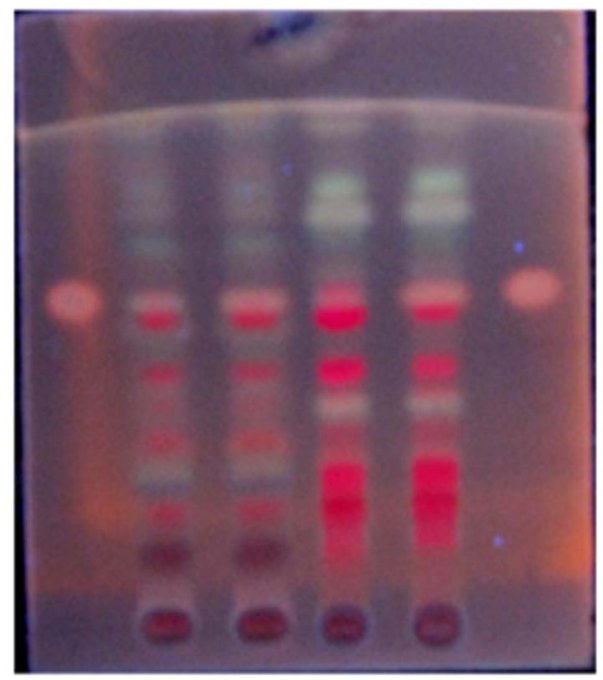

Figure 2. TLC plate showing fluorescent bands visualized in the Camag Scanner 4. Lanes: 1 and 6-Standard, 2-A. pallens leaves, 3-A. pallens leaves spike, 4-A. nilagirica (Kolhapur) leaves, 5-A. nilagirica (Kolhapur) leaves spike.

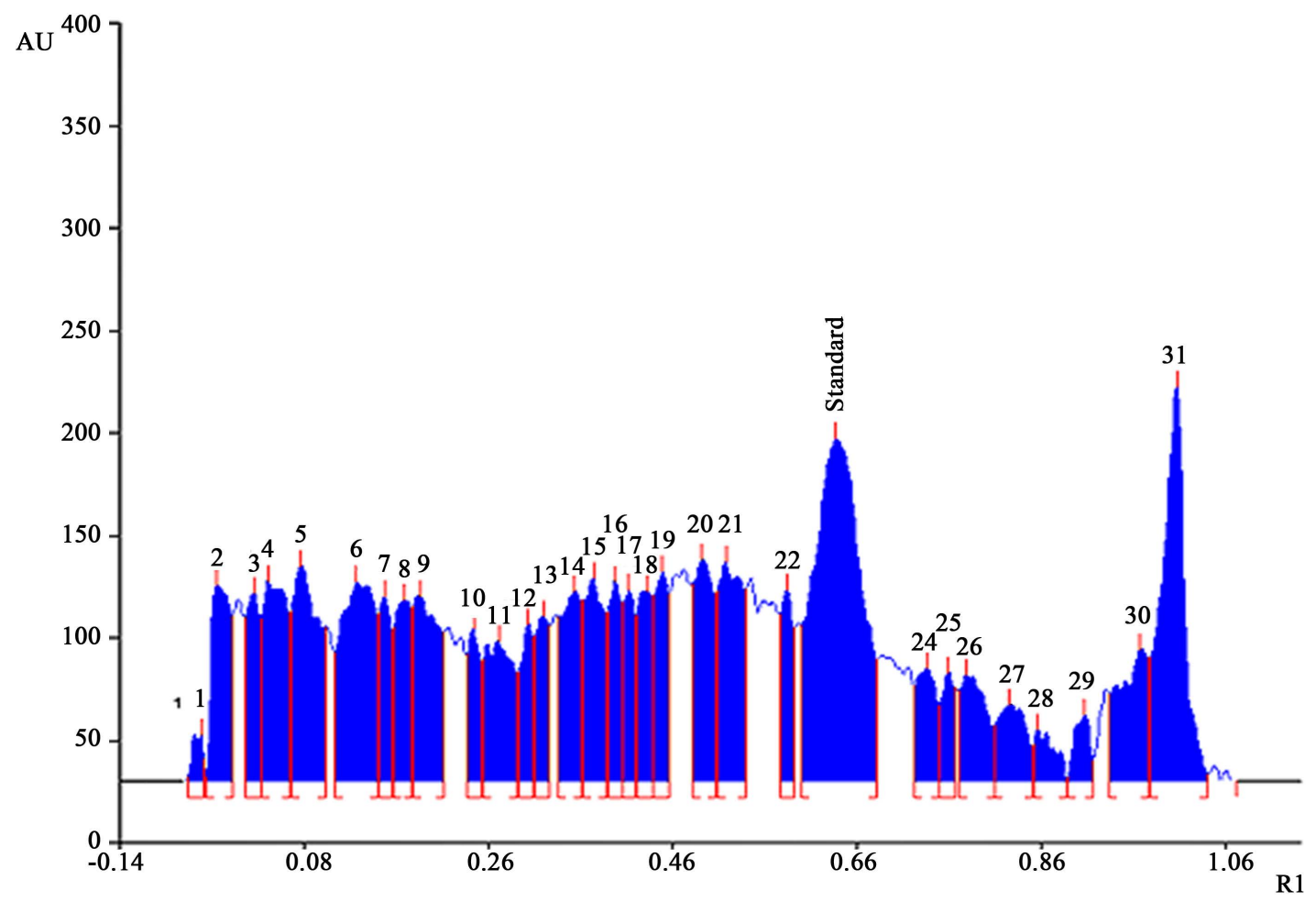

Figure 3. HPTLC graph for standard-artemisinin.

Table 2. HPLC analysis. Retention time of A. pallens, A. nilagirica, A. japonica (RT for standard is 18.7).

\begin{tabular}{cccccc}
\hline \multirow{2}{*}{ Sample } & \multicolumn{2}{c}{ Kolhapur } & \multicolumn{2}{c}{ Panchgani } & \multicolumn{2}{c}{ Lonavala } \\
\cline { 2 - 5 } & A. pallens & A. nilagirica & A. japonica & A. nilagirica & A. nilagirica \\
\hline \multirow{2}{*}{ Leaves } & 19.0 & 18.7 & $\mathbf{1 8 . 4}$ & 18.0 & 18.7 \\
Florets & 19.1 & 18.7 & $\mathbf{1 8 . 3}$ & 18.9 & 18.7 \\
\hline
\end{tabular}




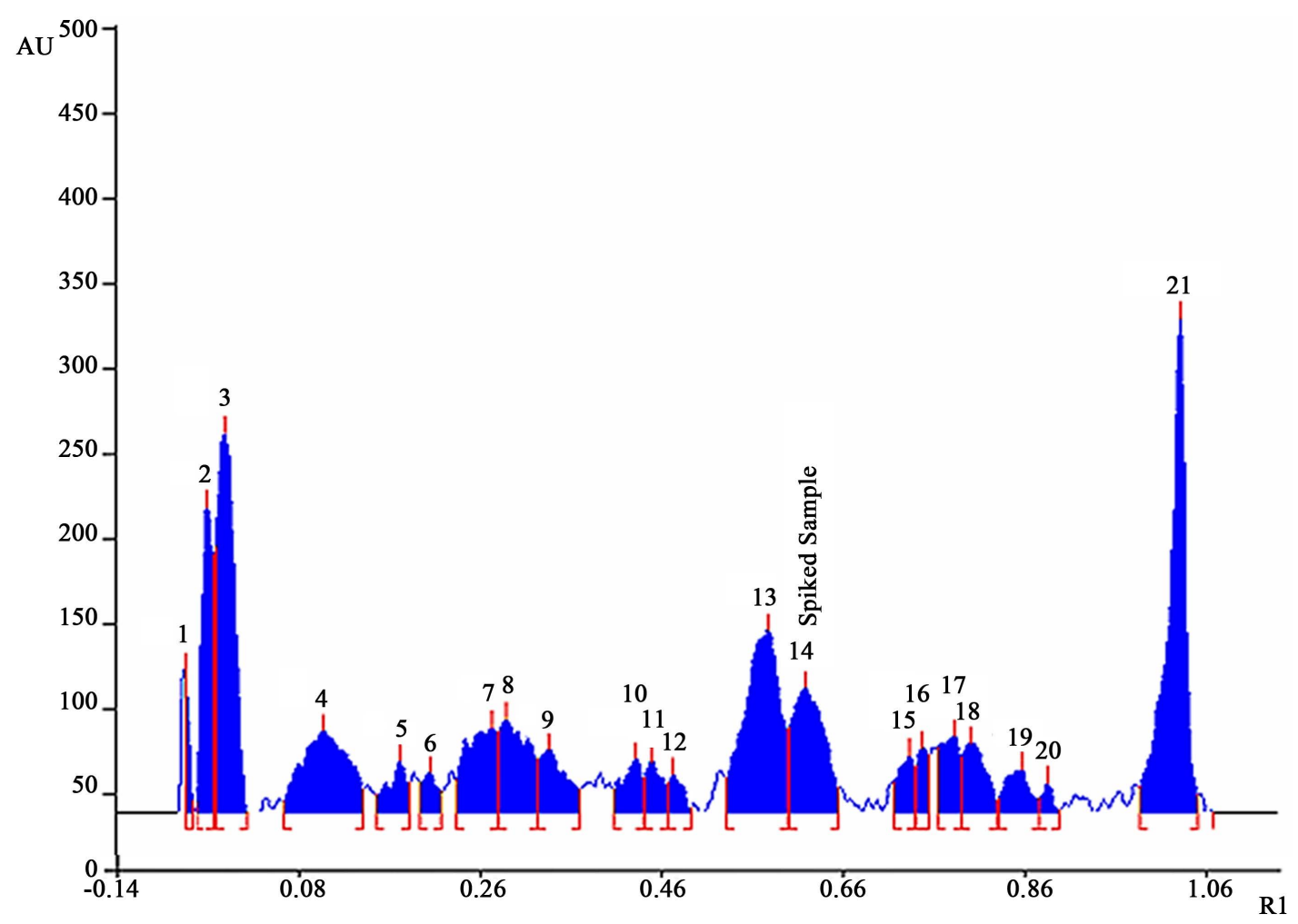

Figure 4. HPTLC graph for spiked sample of A. pallens-leaves.<smiles>C=C1CCC(C(C)C)C2C=C(C)CCC12</smiles>

(1)<smiles>CC1=CCCC2(C)CCC(C(C)(C)O)CC12</smiles>

(2)<smiles>CC1=CC2C(=C(C)CO)CCC(C)C2CC1</smiles>

(3)

Figure 5. Important bicyclic sesquiterpenes in Artemisia nilagirica. (1) Naphthalene,1,2,3,4,4a,5,6,8a-octahydro-

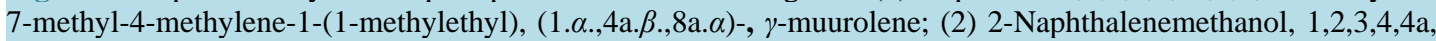

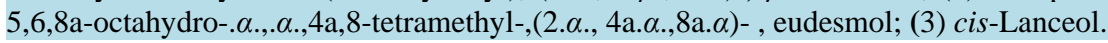

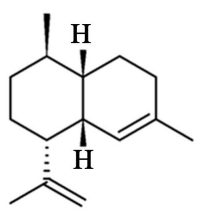

(1R,4R,4aS,8aR)-4,7-dimethyl-1-prop-1-en-2-yl-1,2,3,4,4a,5,6,8a-octahydronaphthalene)

Figure 6. Structure and IUPAC name of amorpha-4,11-diene.

Table 3. Concentration of artemisinin in A. japonica.

\begin{tabular}{cccc}
\hline A. Japonica (Panchagani) & Retention Time & Area & Concentration (mg/g) \\
\hline Leaves & 18.4 & 660720 & 1.3 \\
Florets & 18.3 & 192926 & 0.4205 \\
\hline
\end{tabular}


Table 4. GC-MS analysis of standard artemisisnin.

Sr. No. Name of the compound Mol. wt Structure

Hit

Cyclohexanecarboxylic acid, methyl ester

142<smiles>COC(=O)C1CCCCC1</smiles>

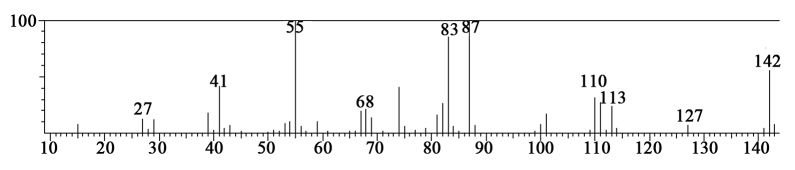

2

Ethyl 2-cyclopentanone

152<smiles>CCOC(=O)C1CCCC1=O</smiles>

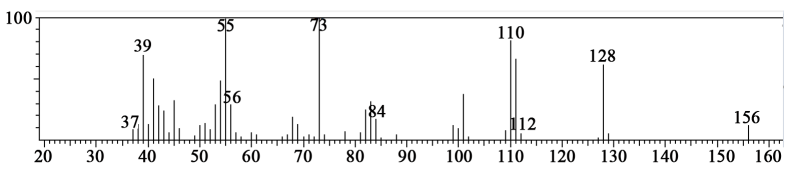

3

3,4-Dihydro-2H-pyran-

2-carboxylic acid

128<smiles>O=C(O)C1CCC=CO1</smiles>

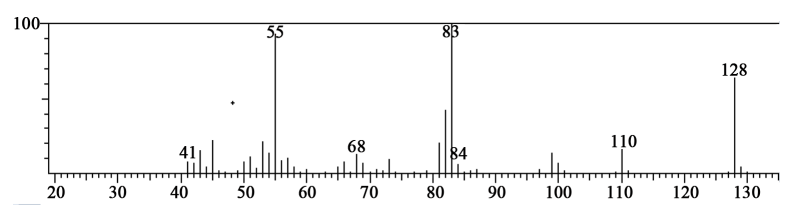

156<smiles>CCOC(=O)c1cnc(O)[nH]1</smiles>

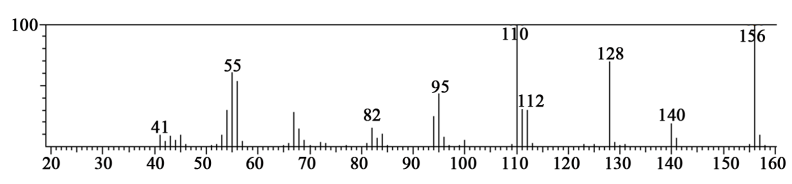

5

Isoaromadendrene epoxide

220
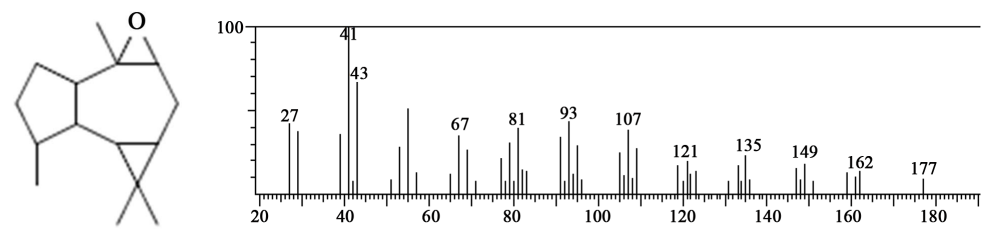

222
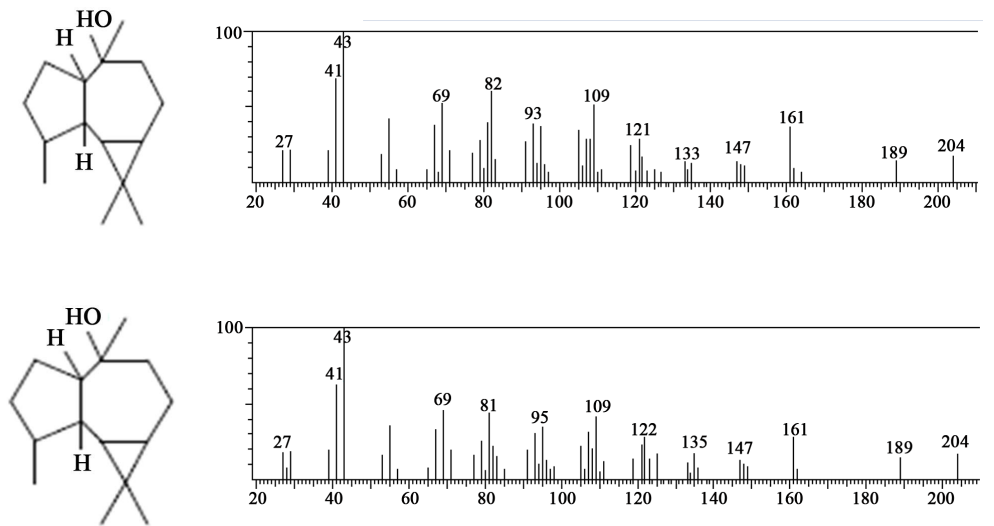

222

Globulol
Epiglobulol

7

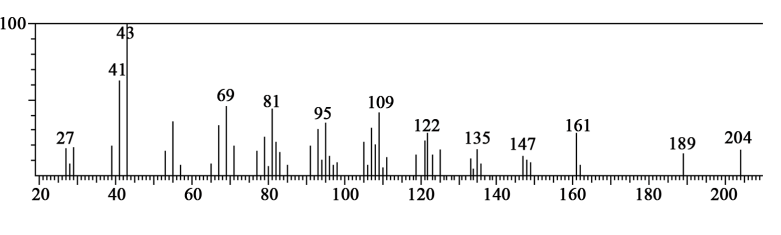




\section{Continued}

8

Thunbergol

Indan, 3a,4,5,6,7,7a-betahexahydro-2alpha-isopropyl

10

1-Buten-3-one,

1-(1-acetyl-5,

5-dimethylcyclopentyl)-

2,4,4-Trimethyl-3(3-methylbutyl) cyclohex-2-enone

12
290<smiles>C=C(CCCC(C)C)CCC(C=CC(C)(O)c1ccccc1)C(C)C</smiles>

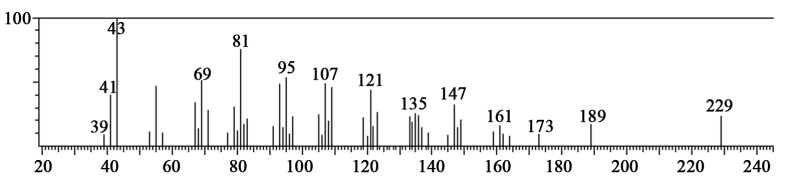

208
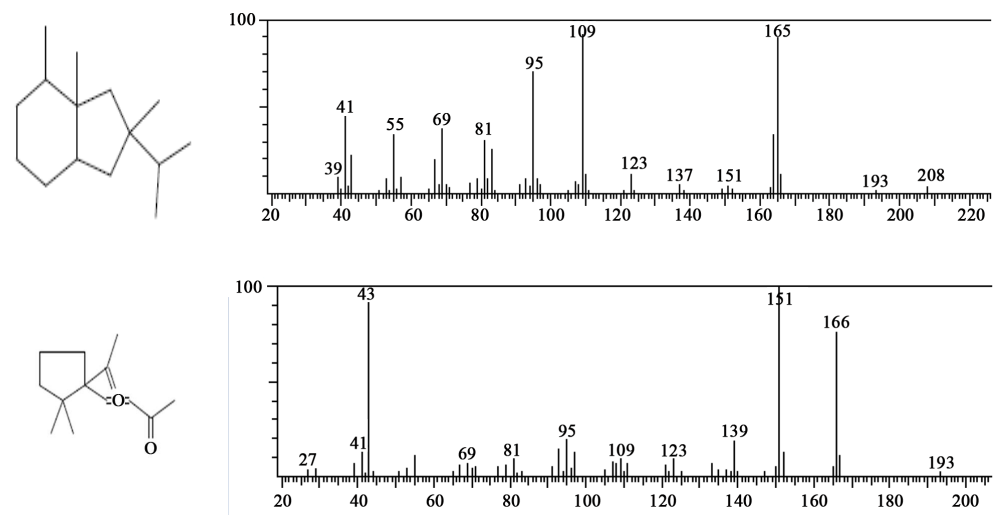

208<smiles>CC(=O)OC12CCCC1(C)C(C)O2</smiles><smiles>CC1=C(CCC(C)C)C(C)(C)CCC1=O</smiles>
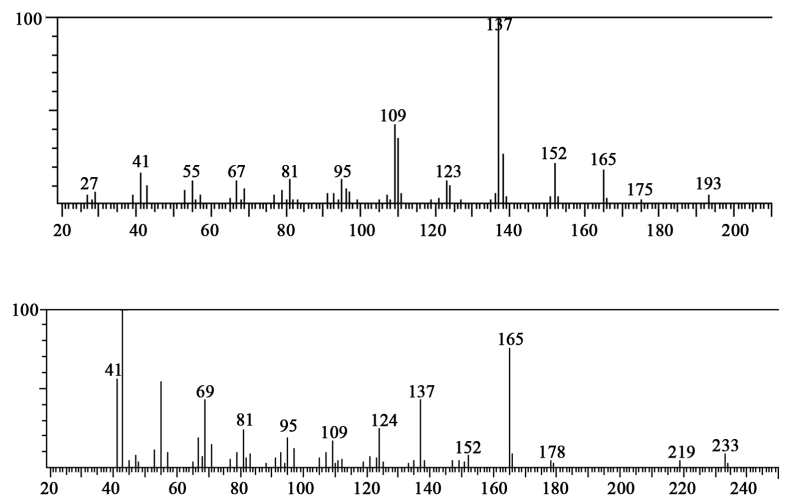

formed cation (C-7 bisabolyl) is deprotonated to an unknown intermediate which further results into C-1 bisabolylcation after a 1,3-hydride shift. This cation with positive charge at $\mathrm{C} 1$ promotes a nucleophillic attack by the double bond C10-C11, thus second ring closes to form a C-11 amorphanecation. Finally, deprotonation on C12 or $\mathrm{C} 13$ gives $\gamma$-muurolene.

\subsubsection{Formation of $\gamma$-Muurolene from FPP by Germacrene D Synthase and $\gamma$-Humulene Synthase}

The work on Germacrene D and $\gamma$-Muurolene by Setzer (2008) and Yoshihara et al. (1969) is reinvestigated [27] [28]. Formation of $\gamma$-muurolene from FPP by possible two different enzymes, Germacrene D synthase and $\gamma$-humulene synthase is illustrated (Figure 8). Initially, Germacrene D synthase ionizes the diphosphate anion and invert the stereochemical situation of carbon atom under attack. This situation brings C1 in close proximity to $\mathrm{C} 6$ that result into bond formation between these two carbon atoms forcing first ring closure to give Germacrene D. This Germacrene sesquiterpene accepts a proton to undergo a series of hydride shifts forming Muurolenylcation. The formed cation is deprotonated to give $\gamma$-Muurolene.

Besides, highly conserved DDxxD sequence found in all terpene synthases, additional DDxxD motif in $\gamma$ humulene synthase (residues 487 - 491) employs multiple product formation resulting from diphosphate binding at these conserved sites [29] [30]. Firstly, $\gamma$-humulene synthase with an exceptional divalent cation ionizes diphosphate anion and forms Nerolidylcation with positively charged C1 atom. The formed cation allows nucleophillic attack on C1 by C10-C11 double bond causing first ring closure to form Germacrylcation. The positively 
Table 5. GC-MS analysis of A. nilagirica (Kolhapur)—-leaves, ethyl acetate extract.

Sr. No.

1.

Cis-verbenol

d-verbenol

2,6-Dimethyl-

3 3,5,7-octatriene-2-ol

Caryophyllene

4

Beta-sesquiphelandrene

(Z)-beta-farnesene

Cedrene

204

8

Germacrene D
152<smiles>CC1=CC(O)C2CC1C2(C)C</smiles>

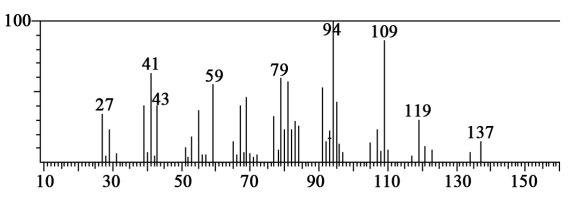

152<smiles>CC1=CC(O)C2CC1C21CC1</smiles>

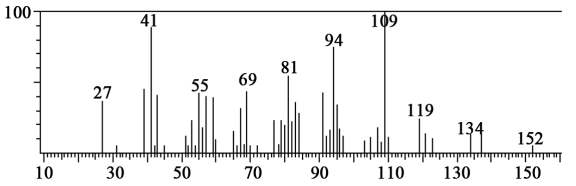

152<smiles>C=C/C(C)=C/C=C/C(C)(C)O</smiles>
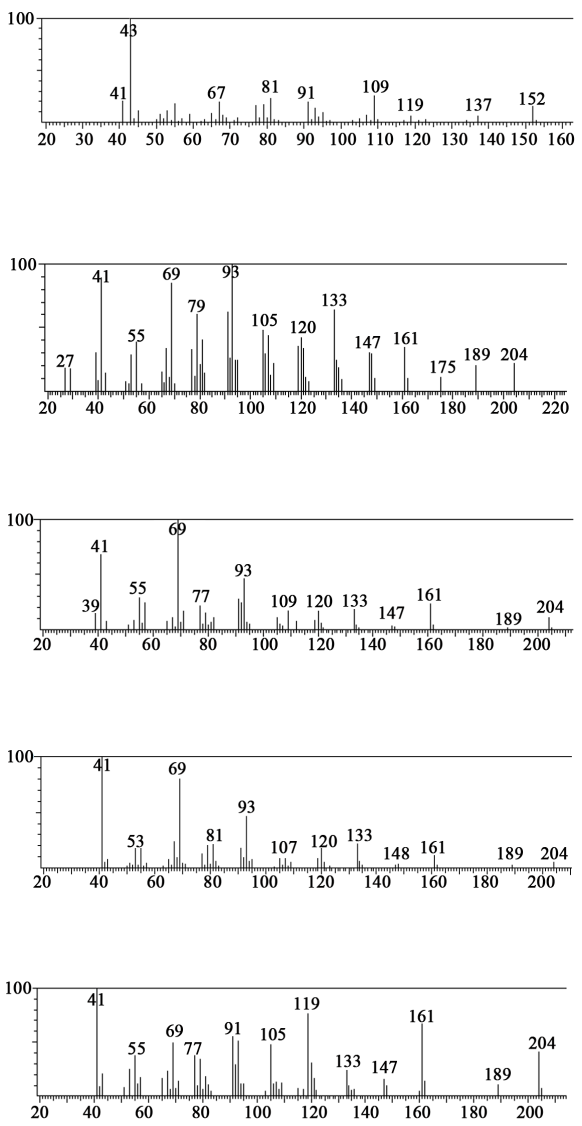<smiles>C=C/C=C\C(CC/C(C)=C\CCC)C(C)C</smiles>

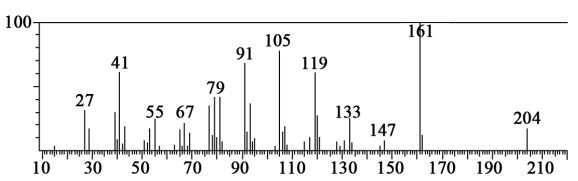


Naphthalene,

1,2,3,4,4a,5,6,8a-octahydro-7methyl-4-methylene-1(1-methylethyl)-,

(1.alpha.,4a.alpha.,8a.alpha.)

10.

Caryophyllene oxide

11

Lanceol

12

13

14.

Eudesmol

15.

n-hexadeconic acid

5,6,6-Trimethyl-5-

17. (3-oxobut-1-enyl)-1-oxaspiro [2.5]octan-4-one<smiles>C=C1CCC(C(C)C)[C@@H]2C=C(C)CC[C@H]12</smiles>

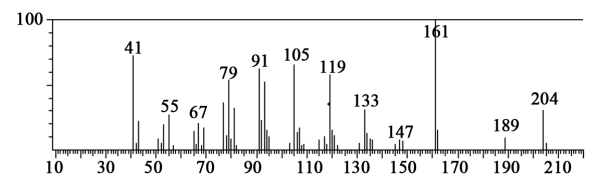<smiles>C=C1CCC2OC2(C)CCC2C1CC2(C)C</smiles>

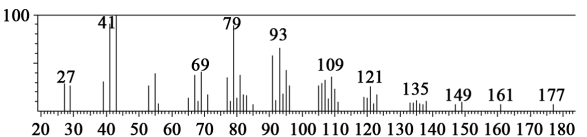<smiles>CC1=CC2C(=C(C)CO)CCC(C)C2CC1</smiles>

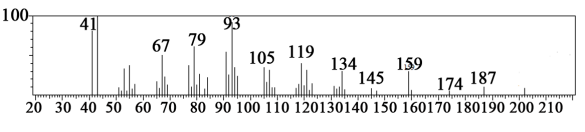

220
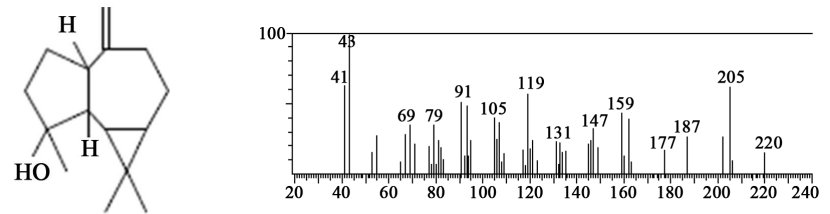<smiles>C=C1CCC2C(C3C1CCC3(C)C)C2(C)O</smiles>

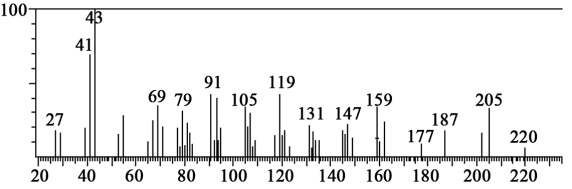<smiles>CC1CCCC2(C)CCC(C(C)(C)O)C=C12</smiles>
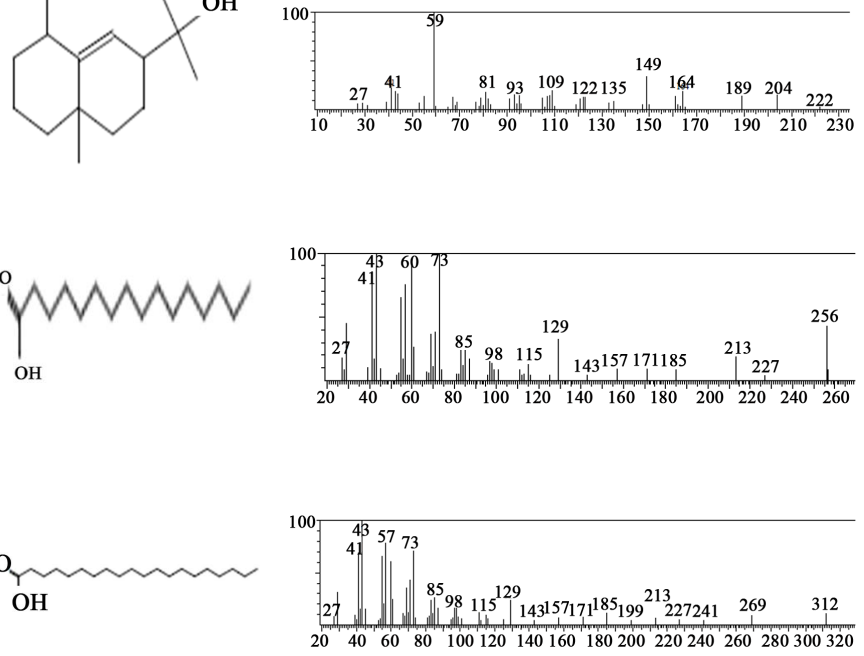

OH<smiles>CC(=O)/C=C/C1(C)C(=O)C2(CCC1(C)C)CO2</smiles>

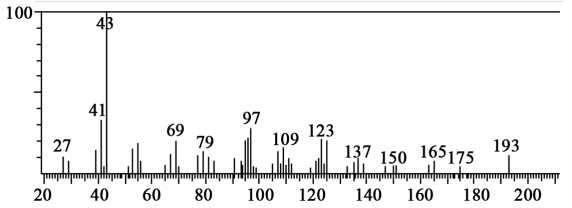




\section{Continued}

18.

Beta-carotene

536

grumbury

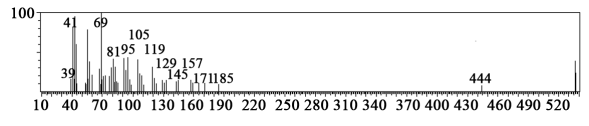

19.

Provitam-in D4

398

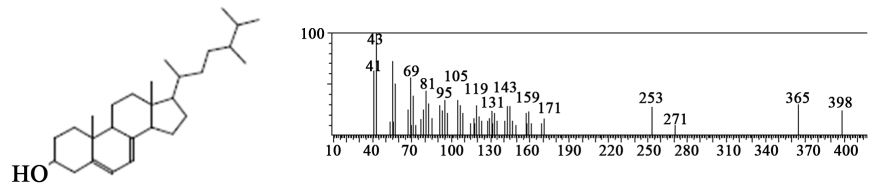

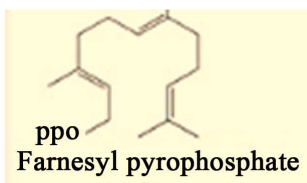

Farnesyl pyrophosphate

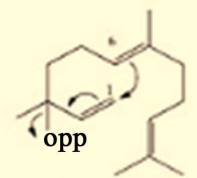

Nerolidyl diphosphate
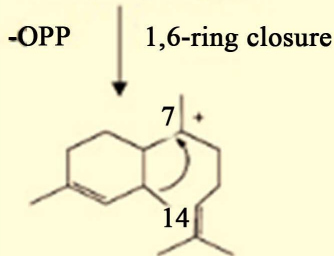

C-7 Bisabolyl cation

1,3-hydride shift

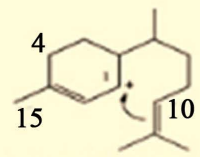

C-1 Bisabolyl cation

1,10-ring closure

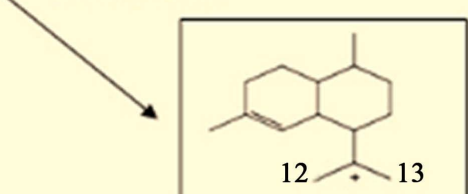

C-11 Amorphanecation

$-\mathrm{H}^{+}$

Amorpha 4,11-diene

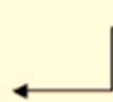

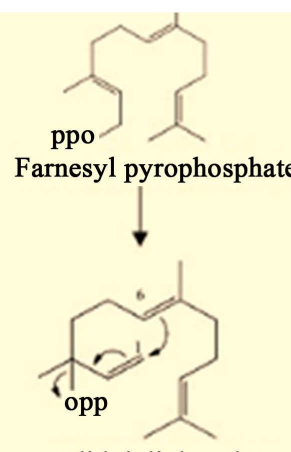

Nerolidyl diphosphate
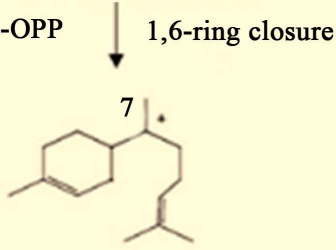

C-7 Bisabolyl cation

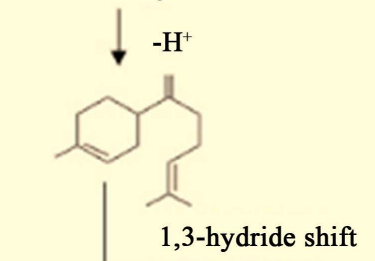

1,10-ring closure

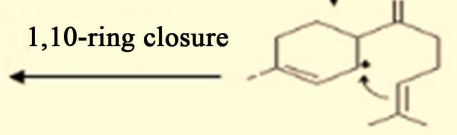

C-1 Bisabolyl cation

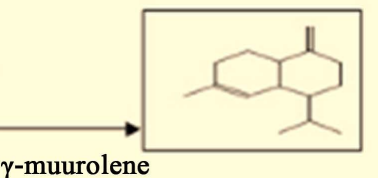

Figure 7. Predicted pathway showing the formation of $\gamma$-muurolene instead of amorpha 4,11diene catalysed by amorpha 4,11-diene. 


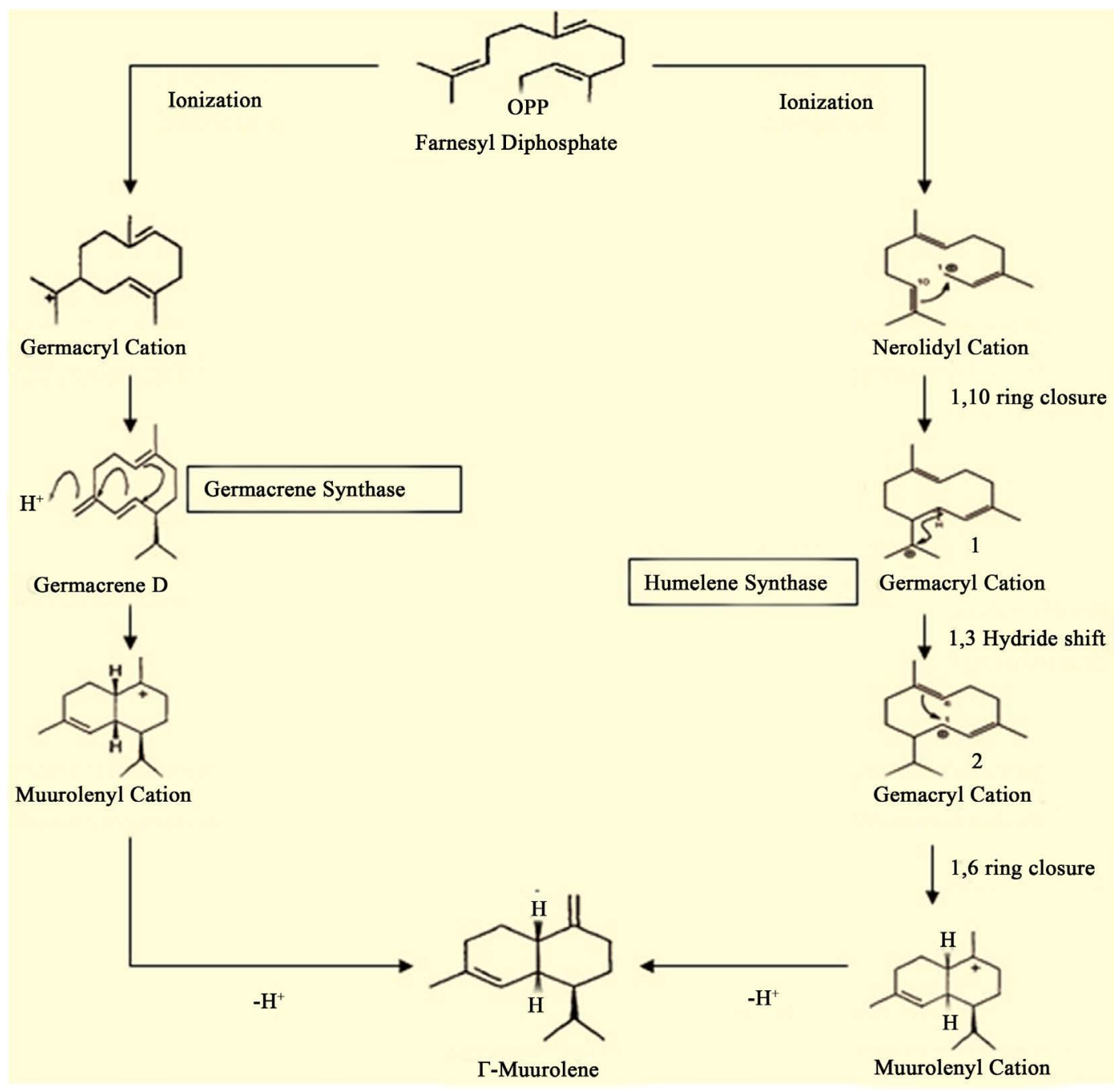

Figure 8. Proposed pathway for the formation of $\gamma$-muurolene from germacrene D catalyzed by germacrene synthase and from farnesyl diphosphate by humelene synthase.

charged C11 in Germacrylcation forces a 1,3-hydride shift to give another Germacrylcation leaving a positive charge at C1 atom. Through a nucleophillic attack on C1 atom by C5-C6 double bond promotes second ring closure to form Muurolenylcation. Further, formed cation forces a proton at C7 position out of the structure to give $\gamma$-muurolene.

\section{Conclusion}

This study reported screening of new plant sources of artemisinin from different regions of India. The content of artemisinin in A. japonica was significantly lower when compared to A. annua. Further, elicitors can be used to increase the concentration of artemisinin in tissue cultures of $A$. japonica. Structures present in ethyl acetate extract of $A$. nilagirica explore the biosynthetic mechanism involved in artemisinin formation from its precursor amorpha, 4,11-diene. The pathway can be further analyzed to identify any possible intermediate or derivative of artemisinin in A. nilagirica.

\section{Experimental}

\subsection{Plant Material}

The species were collected from different regions in Western Ghats of Maharashtra. A. pallens was collected 
from Shikharshinganapur, Satara and Jyotiba hill, Kolhapur. A. nilagirica was collected from Panhala fort (Kolhapur), Panchgani (Mahabaleshwar) and Pawana hill (Lonavala). Furthermore, Artemisia japonica was collected from Panchgani (Mahabaleshwar). The species were authenticated by taxonomist at Department of Botany, Shivaji University, Kolhapur. The samples were air dried at room temperature in well ventilated room.

\subsection{Standard Preparation}

Artemisinin (98\% pure) was obtained from Sigma-Aldrich and dissolved in acetonitrile at $1 \mathrm{mg} / \mathrm{ml}$ concentration.

\subsection{TLC Analysis}

\subsubsection{Extract Preparation}

Plant material $(1 \mathrm{gm})$ of respective species was weighed and crushed to fine powdered using liquid nitrogen. Two different extracts were prepared in $20 \mathrm{ml}$ of hexane and dichloromethane separately. The mixture of powdered plant material and respective solvents was incubated for $6-7 \mathrm{~h}$ in shaker at $150 \mathrm{RPM}$ at room temperature. After incubation, $2 \mathrm{ml}$ of filtrate was lyophilized in water bath at $80^{\circ} \mathrm{C}-90^{\circ} \mathrm{C}$. Acetonitrile was added and ultra-sonicated for 2 - 3 seconds ( 80 watt, 220 V AC). Finally, filtrate was centrifuged at 10,000 rpm and supernatant was used as test solution.

\subsubsection{Chromatography}

The samples were applied to the TLC Si $60 \mathrm{~F}_{254}, 10 \times 10 \mathrm{~cm}$ (Merck) plate as a $5 \mathrm{~mm}$ spot or $10 \mathrm{~mm}$ band, 1 $\mathrm{cm}$ apart at $1 \mathrm{~cm}$ height from the lower edge of the plate. After complete air drying, plate was placed in a TLC chamber saturated with mobile phase as Hexane:Diethylether [1:1], and allowed to run till the front of mobile phase reached to the upper edge of the plate. After running plate was air dried and dipped into anisaldehyde developing agent for 10 - 15 seconds (anisaldehyde developing agent was prepared by slowly adding $9 \mathrm{ml}$ of $98 \%$ sulphuric acid to an ice cooled mixture of $85 \mathrm{ml}$ of methanol and $10 \mathrm{ml}$ of glacial acetic acid). Plate was air dried and incubated at $100^{\circ} \mathrm{C}$ for $5-7 \mathrm{~min}$ for spot development and examined visually.

\subsection{HPTLC Analysis}

\subsubsection{Extract Preparation}

Dried plant material $(200 \mathrm{mg}$ ) was mixed with $10 \mathrm{ml}$ of toluene and sonicated for $10 \mathrm{~min}$. Mixture was centrifuged at 10,000 rpm, and supernatant was used as test solution for screening.

\subsubsection{Chromatography}

The samples $(20 \mu \mathrm{l})$ were applied by automated injection system on HPTLC Si $60 \mathrm{~F}_{254}, 10 \times 10 \mathrm{~cm}$ (Merck) plate and air dried. Plate was placed in a chromatographic chamber saturated with Cyclohexane, Ethyl acetate, Acetic acid [20:10:1] and allowed to run till the front of mobile phase reaches at $3 / 4^{\text {th }}$ height of the TLC plate. After air drying, plate was developed using anisaldehyde reagent by immersing for $10-15 \mathrm{~s}$. Then plate was air dried and heated to $100^{\circ} \mathrm{C}$ for $5-7 \mathrm{~min}$ and examined under Camag Scanner 4 .

\subsection{Quantification of Artemisinin by HPLC}

Different HPLC systems were used to analyze artemisinin in different plant extracts. Waters HPLC (model 2487), using a hypersil C18 reversed phase column $15 \mathrm{~cm}$ with $5 \mu$ particle size and Agilent 1200 series, using zorbax SB-C18, $250 \mathrm{~mm} \times 4.6 \mathrm{~mm}, 5 \mu \mathrm{m}$, prepacked column. A constant rate of $1 \mathrm{ml} / \mathrm{min}$ was used with two mobile phases: $[\mathrm{A}]$ acetonitrile: water $[50: 50]$ and solvent $[\mathrm{B}]$ acetonitrile. The elution was performed employing a program from [A]-100\% [ $\mathrm{t}=0 \mathrm{~min}], 2 \%$ [ $\mathrm{t}=30-40 \mathrm{~min}]$, to [B]-0\% in a period of 60 minute and detected at $211 \mathrm{~nm}$ [UV-VIS]. The retention time of sample peak obtained was compared with that of standard.

\subsection{Finger Printing by GC-MS}

\subsubsection{Standard Preparation}

Prepared standard $(1 \mathrm{mg} / \mathrm{ml})$ was completely evaporated and dissolved in $1 \mathrm{ml}$ of methanol. 


\subsubsection{Extract Preparation}

Air dried leaves (1 gm) were powdered using liquid nitrogen. Two extracts were prepared in $20 \mathrm{ml}$ of methanol and ethyl acetate and incubated overnight at room temperature. This mixture was centrifuged at $5000 \mathrm{rpm}$ for 10 min and supernatant was collected. The supernatant was treated with activated charcoal and centrifuged at 12,000 rpm for $10 \mathrm{~min}$. The supernatant obtained was filtered through $0.22 \mu$ filter and used for analysis.

\subsubsection{Method}

Analysis was performed on Agilent 5973 Mass Selective Detector coupled to anagilent 6890 N Gas Chromatograph using G1701 MSD Chemstation software and equipped with a $30 \mathrm{M} \times 0.25 \mathrm{~mm}$ DB-5MS column with $0.25 \mu \mathrm{m}$ film thickness. The chromatograph conditions were a split injection [20:1] onto the column using a helium flow of $0.4 \mathrm{ml} / \mathrm{min}$ and temperature programmed with either initial temperature of $70^{\circ} \mathrm{C}$ for $1 \mathrm{~min}$ or temperature ramped at $10^{\circ} \mathrm{C} / \mathrm{min}$ to $300^{\circ} \mathrm{C}$ and held for $10 \mathrm{~min}$. The mass selective detector was run under standard $\mathrm{EI}+$ conditions scanning on effective mass ranging from 40 to 1000 at 2.26 scan/second.

\section{Acknowledgements}

We thank Dr. Sandeep Kale for providing HPLC facility at DBT-ICT Centre for Energy Biosciences, Institute of Chemical Technology, Mumbai, India. HPTLC and GC-MS facility was provided by Prof. S.R.Yadave at Department of Botany, Shivaji University, Kolhapur, India.

\section{References}

[1] Mcvaugh, R. (1984) Flora Novo-Galiciana: A Descriptive Account of the Vascular Plants of Western Mexico Vol. 12. Anderson, W.R., Ed., University of Michigun Press, Ann Arbor.

[2] Singh, A., Kaul, V.K., Mahajan, V.P., Singh, A., Mishra, L.N., Thakur, R.S. and Hussain, A. (1986) Introduction of Artemisia annua in India and Isolation of Artemisinin, a Promising Anti Malarial Drug. Indian Journal of Pharmaceutical Sciences, 48, 137-138.

[3] Rathore, D., McCutchan, T.F., Sullivan, M. and Kumar, S. (2005) Antimalarial Drugs: Current Status and New Developments. Expert Opinion on Investigational Drugs, 14, 871-883. http://dx.doi.org/10.1517/13543784.14.7.871

[4] Acton, N., Klayman, D.L. and Rollman, I.J. (1985) Reductive Electrochemical HPLC Assay for Artemisinin [Quinghaosu]. Planta Medica, 51, 445-446. http://dx.doi.org/10.1055/s-2007-969545

[5] Charles, D.J., Simon, J.E., Wood, K.V. and Heinstein, P. (1990) Germplasm Variation in Artemisinin Content of Artemisia annua Using Alternative Method of Artemisinin Analysis from Crude Plant Extract. Journal of Natural Products, 53, 157-160. http://dx.doi.org/10.1021/np50067a021

[6] Duke, S.O. and Paul, R.N. (1993) Development and Fine Structure of Glandular Trichomes of Artemisia annua L. International Journal of Plant Sciences, 154, 107-118. http://dx.doi.org/10.1086/297096

[7] Martinez, B.C. and Staba, J. (1988) The Production of Artemisinin in Artemisia annua L. Tissue Cultures. Advances in Cell Culture, 6, 69-87. http://dx.doi.org/10.1016/b978-0-12-007906-3.50009-7

[8] Ramachandra, R.S. and Ravishankar, G.A. (2002) Plant Cell Cultures: Chemical Factories of Secondary Metabolite. Biotechnology Advances, 20, 101-153. http://dx.doi.org/10.1016/S0734-9750(02)00007-1

[9] Li, M.Y., Jiang, F.S., Yu, X.L. and Miao, Z.Q. (2015) Engineering Isoprenoid Biosynthesis in Artemisia annua L. for the Production of Taxadiene: A Key Intermediate of Taxol. BioMed Research International, 2015, Article ID: 504932. http://dx.doi.org/10.1155/2015/504932

[10] Putalun, W., Luealon, W., De-Eknamkul, W., Tanaka, H. and Shoyama, Y. (2007) Improvement of Artemisinin Production by Chitosan in Hairy Root Cultures of Artemisia annua L. Biotechnology Letters, 29, 1143-1146. http://dx.doi.org/10.1007/s10529-007-9368-8

[11] Paniego, N.B. and Giulietti, A.M. (1996) Artemisinin Production by Artemisia annua L.-Transformed Organ Cultures. Enzymes and Microbial Technologies, 18, 526-530. http://dx.doi.org/10.1016/0141-0229(95)00216-2

[12] White, N.J. (2008) Qinghaosu (Artemisinin): The Price of Success. Science, 320, 330-334. http://dx.doi.org/10.1126/science.1155165

[13] Laughlin, J.C. (1994) Agricultural Production of Artemisinin-A Review. Transactions of the Royal Society of Tropical Medicine and Hygiene, 88, 21-22. http://dx.doi.org/10.1016/0035-9203(94)90465-0

[14] Deblays, N., Benakis, A. and Collet, G. (1993) Selection and Breeding of High Artemisinin (Qinghaosu) Yielding Strains of Artemisia annua. Acta Horticulturae, 330, 203-206.

[15] Woerdenbag, H.J., Pras, N., Chan, N.G., Bang, B.T., Bos, R., van Uden, W., Van, Y.P., Van Boi, N., Batterman, S. and 
Luqt, C.B. (1994) Artemisinin, Related Sesquiterpenes, and Essential Oil in Artemisia annua during a Vegetation Period in Vietnam. Planta Medica, 60, 272-275. http://dx.doi.org/10.1055/s-2006-959474

[16] Haynes, R.K. (2006) From Artemisinin to New Artemisinin Antimalarials: Biosynthesis, Extraction, Old and New Derivatives, Stereochemistry and Medicinal Chemistry Requirements. Current Topics in Medicinal Chemistry, 6, 509-537. http://dx.doi.org/10.2174/156802606776743129

[17] Lin, A.J., Klayman, D.L., Hoch, J.M., Silverton, J.V. and George, C.F. (1985) Thermal Rearrangement and Decomposition Products of Artemisinin (Qinghauso). The Journal of Organic Chemistry, 50, 4504-4508. http://dx.doi.org/10.1021/jo00223a017

[18] Theoharides, A.D., Smyth, M.H., Ashmore, A.W., Halverson, J.M., Zhou, Z.M., Rider, W.E. and Lin, A.J. (1988) Determination of Dihydroqinghaosu in Blood by Pyrolysis Gas Chromatography/Mass Spectrometry. Analytical Chemistry, 60, 115-120. http://dx.doi.org/10.1021/ac00153a004

[19] Ferriera, J.F. and Gonzalez, J.M. (2009) Analysis of Underivatized Artemisinin and Related Sesquiterpene Lactones by High-Performance Liquid Chromatography with Ultraviolet Detection. Phytochemical Analysis, 20, 91-97. http://dx.doi.org/10.1002/pca.1101

[20] Bouwmeester, H.J., Wallart, T.E., Jannsen, M.H., Van Loo, B., Jansen, B.J., Posthumus, M.A., Schmidt, C.O., De Kraker, J.W., Konig, W.A. and Franssen, M.C. (1999) Amorpha-4,11-diene Synthase Catalyses the First Probable Step in Artemisinin Biosynthesis. Phytochemistry, 52, 843-854. http://dx.doi.org/10.1016/S0031-9422(99)00206-X

[21] Brown, G.D. (2010) The Biosynthesis of Artemisinin (Qinghauso) and the Phytochemistry of Artemisia annua L. (Quinghao). Molecules, 15, 7603-7698. http://dx.doi.org/10.3390/molecules15117603

[22] Starks, C.M., Black, K., Chappell, J. and Noel, J.P. (1997) Structural Basis for Cyclic Terpene Biosynthesis by Tobacco 5-Epi-Aristocholene Synthase. Science, 277, 1815-1820. http://dx.doi.org/10.1126/science.277.5333.1815

[23] Colby, S.M., Alonso, W.A., Katahira, E.J., Mcgarvey, D.J. and Croteau, R. (1993) 4S-Limonene Synthase from the Oil Glands of Spearmint (Mentha spicata): cDNA Isolation, Characterization and the Bacterial Expression of the Catalytically Active Monoterpene Cyclise. The Journal of Biological Chemistry, 268, 23016-23024.

[24] Desjardins, A.E., Hohn, T.M. and Mccormick, S.P. (1993) Trichothecene Biosynthesis in Fusarium Species: Chemistry, Genetics and Significance. Microbiology Reviews, 57, 595-604.

[25] Hohn, T.M. and Beremand, P.D. (1989) Isolation and Nucleotide Sequence of a Sequiterpene Cyclase Gene from the Trichothecene-Producing Fungus Fusarium sporotrichioides. Gene, 79, 131-138. http://dx.doi.org/10.1016/0378-1119(89)90098-X

[26] Proctor, R.H. and Hohn, T.M. (1993) Aristolochene Synthase: Isolation, Characterization and Bacterial Expression of a Sesquiterpenoid Biosynthetic Gene (Aril) from Penicillium roqueforti. The Journal of Biological Chemistry, 268, 4543-4548.

[27] Setzer, W.N. (2008) Germacrene D Cyclization: An Ab Initio Investigation. International Journal of Molecular Sciences, 9, 89-97. http://dx.doi.org/10.3390/ijms9010089

[28] Yoshihara, K., Ohta, Y., Sakai, T. and Hirose, Y. (1969) Germacrene D: A Key Intermediate of Cadinene Compounds and Bourbonenes. Tetrahedron Letters, 27, 2263-2264. http://dx.doi.org/10.1016/S0040-4039(01)88136-3

[29] Williams, D.C., McGarvey, D.J., Katahira, E.J. and Croteau, R. (1998) Truncation of Limonene Synthase Preprotein Provides a Fully Active 'Pseudomature' Form of This Monoterpene Cyclase and Reveals the Function of the Amino-Terminal Arginine Pair. Biochemistry, 37, 12213-12220. http://dx.doi.org/10.1021/bi980854k

[30] Cane, D.E., Yang, G., Xue, Q. and Shim, J.H. (1995) Trichodiene Synthase. Substrate Specificity and Inhibition. Biochemistry, 34, 2471-2479. http://dx.doi.org/10.1021/bi00008a010 